
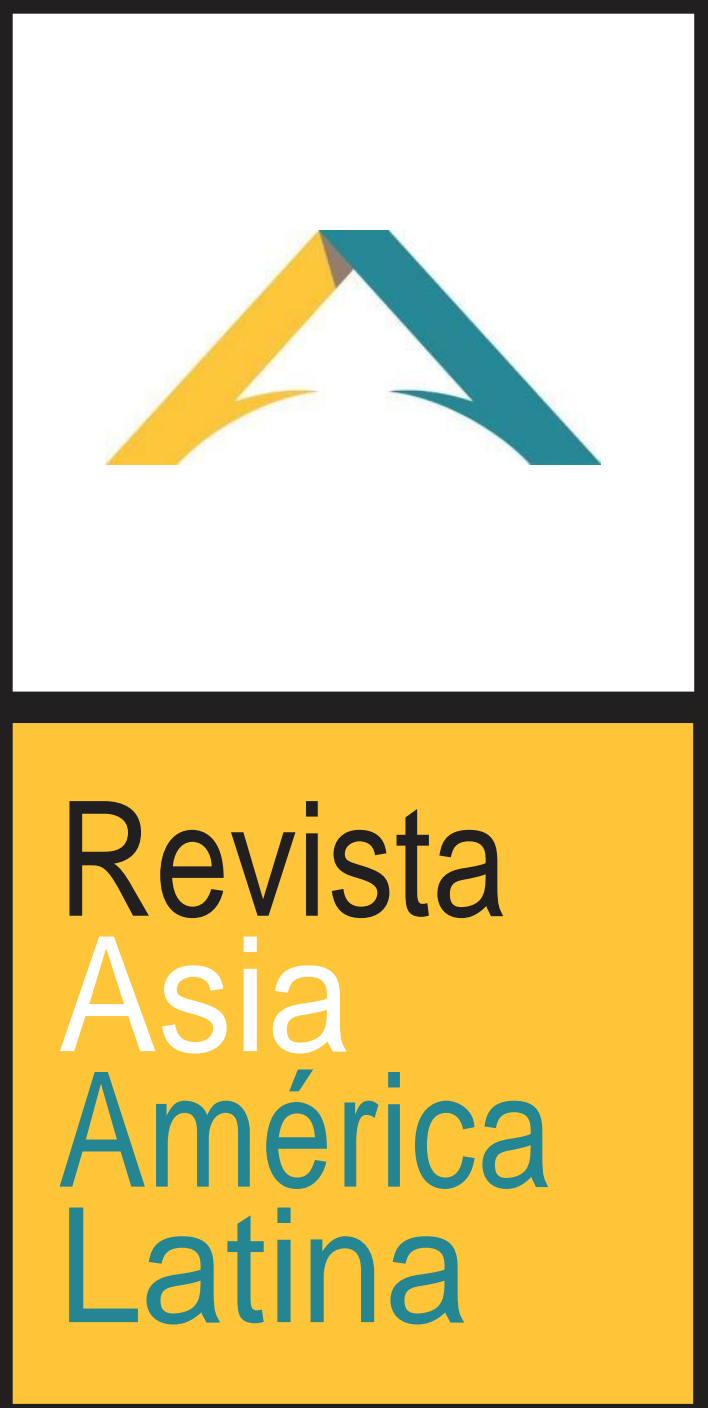

ISSN 2524-9347

Grupo de Estudios sobre Asia y América Latina Instituto de Estudios de América Latina y el Caribe Universidad de Buenos Aires

EU

DE BA 


\section{LU, JIE Y MARTIN CAMPS, EDITORES. TRANSPACIFIC LITERAR Y AND CULTURAL CONNECTION: LATIN AMERICAN INFLUENCE IN ASIA}

Palgrave Macmillan, 2020, 263 pp.

\section{Sebastián Díaz Martínez}

The Graduate Center of The City University of New York sdiazmartinez@gradcenter.cuny.edu

Las investigaciones actuales que se proponen analizar desde un amplio espectro de producciones culturales las relaciones transpacíficas pueden caer en la trampa de reproducir, desde sus enfoques críticos y marcos teóricos, perspectivas definidas por los centros de producción de conocimiento tradicionales localizados en Occidente, y quedando atrapadas en el bucle de sus límites y contradicciones. Las profundas transformaciones en las dinámicas globales hacen cada vez más necesario plantear acercamientos y enfoques diferentes, donde en el Sur Global, en cuanto concepto geopolítico como epistemológico, tanto sitio antiimperialista como de producción de conocimiento, se visibilicen los acercamientos entre Asia y América Latina más allá de los límites del centrismo epistemológico occidental. Los trabajos recopilados por Jie Lu y Martin Camps aspiran en sus acercamientos a trazar vínculos autónomos que desplieguen diálogos y encuentros cada vez más necesarios a la hora de desarrollar estrategias de resistencia ante los dispositivos neocoloniales que no dependen de los centros de dominación políticoepistemológica tradicional. La mayoría de los trabajos compilados, más allá de destacar los resultados de sus objetivos investigativos, se articulan como un gesto político, que propone exceder el silenciamiento y deslegitimación de las relaciones periferia-periferia, para potenciar discusiones y posicionamientos frente a efectos políticos concretos de las cada vez más sofisticadas tecnologías neocoloniales de los centros de poder emergentes.

El libro consta de tres secciones unidas temáticamente. La primera, enfocada en las relaciones entre América Latina y Filipinas, es inaugurada por el agudo capítulo de Ignacio López-Calvo, titulado “A Peripheral, South-South Literary Exchange: Balmori And The Reception Of Latin American Modernismo In The Philippines", donde analiza la relación del escritor filipino Jesús Balmori con el modernismo latinoamericano. Tras identificar cómo la influencia del dicho movimiento le permitió al autor desarrollar un (auto) orientalismo direccionado a la idealización de la cultura japonesa, López-Calvo examina cómo la última novela de Balmori, Pájaros de fuego. Novela filipina de la 
guerra (1945) devela el desencuentro abrupto de las vinculaciones políticas ligadas a sus tendencias literarias, como apoyar la intervención nipona, a partir de su propia experiencia atestiguando la violenta ocupación colonial de Japón en las filipinas. Lo novedoso de la perspectiva de López-Calvo es que expande los vínculos que tradicionalmente enlazan distintos orientalismos al identificar sus rutas no tan evidentes (escritores latinoamericanos siendo la fuente para la autoorientalización, de tendencia europea, de un escritor filipino) y las cuales, al menos en el caso de Balmori, son invisibilizadas hasta el momento en que se hace explícito las violentas relaciones de colonialidad que las condicionan.

El segundo capítulo, titulado "Filipino Poet Jesús Balmori: Testimonials of his Mexican Journey Passing Through Japan (1932-1934)" de Axel Gasquet trabaja también a Jesús Balmori, pero desde las crónicas y poemas del escritor filipino durante sus viajes a México durante 1931 y 1932. El análisis que Gasquet parte del desencanto que experimentó Balmori durante su recorrido en el país americano para exponer las redes de colonialidad vigentes en las producciones literarias vinculadas a la idealización de la hispanidad. Así, se expone cómo los marcos representativos que despliegan deseos y estereotipos en algunas producciones literarias (en este caso, el modernismo) pueden vinculares a redes no tradicionales como las centradas en la experiencia europea. El efecto de Balmori en México es similar a aquel viajero que descubre que los países orientales no son lo que las literaturas orientalistas han escrito. El contraste entre los textos de López-Calvo y Gasquet permiten una visión muy completa de la lectura que Balmori realizó del modernismo latinoamericano: en ambos se desencantó de las promesas idealizantes de la literatura modernista al padecer la violenta ocupación nipona y al ver que el purísimo español de Lugones no es el que se habla en ciudad de México

El último capítulo de la primera sección está escrito por Eugenio Matibag, y se titula: "Transpacific: The Queering of Philippine and Hispanic American Literatures". El objetivo del trabajo es identificar tanto en América Latina como en Filipinas cómo, durante las últimas décadas, ha emergido formas de resistencia ante el legado compartido de la ortodoxia religiosa y sexual heredada de la dominación hispánica. Tras interrogarse si la narrativa gay latinoamericana ofrece modelos similares al tratamiento de la experiencia gay en la subsecuente literatura filipina, Matibag recorre un extenso corpus de autores donde encuentra vínculos en el desarrollo de estrategias que resisten un pasado colonial común, bajo regímenes autoritarios, y que se reinventan en los dos extremos del pacífico ante políticas neo-coloniales, producto de las transformaciones neoliberales que limitan la modernidad gay a una experiencia mediatizada y universal acorde a valores endógenos.

"Shared Issues of Identities, Traumas and Migrant Experiences Across Two Continents" titula la segunda parte del libro, y es inaugurada por el texto de Martin Camps, "Disrupted Nationalisms in Times of War: Young Ha-Kim 
and José Revueltas". El trabajo analiza dos novelas: Flor negra (2012) de Young Ha-Kim, cuyo argumento ronda la experiencia de migrantes coreanos durante la Revolución Mexicana, y Los motivos de Cain (1957), de José Revueltas donde se narra el trauma de un veterano de origen mexicano en la Guerra de Corea. La investigación explora la desterritorialización de las identidades, como también dimensiona las estrategias de colonialidad que operan históricamente desde sus puntos comunes, como Estados Unidos con México y Japón con la península coreana. El texto de Martin Camps es un penetrante ensayo que opera como una disrupción entre nociones clásicas de nacionalismos desde un análisis transfronterizo en las zonas de contacto, y que desarrolla herramientas críticas y teóricas necesarias para abordar temáticas como la identidad, la guerra y el trauma en contextos (cada vez más) trasnacionales.

Miguel Rojas Sotelo desarrolla un intenso e inteligente análisis en su texto "Common Ground: Shared Textuality and Visuality in China and Latin America". Desde un amplio corpus que transita entre lo filmico, lo visual, lo performativo y lo poético, aborda las consecuencias colaterales del proyecto modernizador neoliberal, principalmente los efectos medioambientales de la explotación sistemática de recursos naturales como la precarización y marginalización de los sujetos migrantes. El análisis de Rojas Sotelo atraviesa cuerpos, historias, territorios, paisajes, afectos y trabajo, evidenciando cómo las consecuencias de procesos económicos de explotación global hacen cada vez más cercanos en sus efectos, experiencias y traumas, a territorios tan aparentemente lejanos como la Mongolia interior China, la Guajira colombiana, y la frontera entre México y Estados Unidos. Un trabajo extenso, con un corpus amplio y variado, que construye una narrativa más universal que el proyecto modernizador europeo: la de los cuerpos vulnerados, residuales, migrantes y hasta amputados que habitan geografías que ansían interconectarse.

La segunda parte del libro es concluida con el innovador capítulo de Min Suk Kim, "Korean Reality Television-Travel Shows in Constructing Latin American Cultural Identities (2010-Present)", donde explora la creación de Latinoamérica como espacio lejano, unido por un pasado colonial, en los programas de televisión coreana. Suk Kim propone que se establecen conexiones poscoloniales del Sur Global a través de la historia común del colonialismo, donde Corea del sur no puede ser el "Occidente", y Latinoamérica el "Oriente". Si bien se concluye el reforzamiento, casi estereotipado, que en los programas de televisión se presentan los sujetos latinoamericanos como "pre-modernos" o "no ser tomados con seriedad", abriendo un horizonte investigativo a las conexiones del Sur global, mediadas por la solidaridad de común contesto (pos)colonial donde, pese a la evidente disparidad económica y tecnológica entre Corea del sur y América Latina, aún hay formas de desarrollar lazos, conexiones y redes no mediadas por un centro. 
La tercera parte del libro, "Magical Realism in its Asian Turn", centra las reapropiaciones del "realismo mágico" en países asiáticos. En el caso de Indonesia, Marcos Ramírez Rojas en su artículo "Beauty is a Wound: Retelling Modern Indonesian History Through Magical Realism”, se interroga sobre cómo el Realismo mágico continúa siendo usado para representar complejos procesos históricos poscoloniales en la producción de la nación desde la novela de Eka Kurniawan, Beauty is a Wound. Sin embargo, pese al innovador objetivo, solo tiene de referente a García Márquez para la categoría de "Realismo mágico" (que toma más como concepto estilístico y temático que como producto de un fenómeno editorial también occidentalmente centrado) y no define y se desmarca de los debates que disputan la significación del término central en su trabajo, por lo que su lectura se limita asociaciones entre la novela de Kurniawan y Cien años de soledad.

El siguiente capítulo, "Representing History, Trauma and Marginality in Chinese Magical Realist Films" de Jie Lu, abarca el realismo mágico desde recientes producciones cinematográficas chinas (The Sun Also Rises y Hello Mr. Tree). Desde un diálogo con postulados de Frederic Jameson y otros, Lu destaca la apropiación del realismo mágico como una forma de hacer inteligible la experiencia del trauma, bien sea en momentos históricos coyunturales como en una crítica a los procesos de industrialización y urbanización posibilitado por las estrategias de desarrollo económico. El valioso aporte de Lu, además de trazar una ruta metodológica y analítica para la aproximación de una categoría literaria al lenguaje cinematográfico, radica también en resaltar el "realismo" en el "realismo mágico" (tal como retoma de Rushdie), desde su apropiación técnica y artes visuales chinas para evidenciar su potencial político y crítico.

El libro cierra con el texto de "Transcotinental Jouney Of Magical Realism: A Study Of Indian Literatures' Response" de Vibha Maurya, donde indaga la presencia del realismo mágico en obras literarias de la India. Si bien parece dirigirse a un público mayoritariamente hindú, en parte debida a la contextualización histórico-política que hace de Latinoamérica, logra desmarcarse del prisma teórico europeo en su análisis del realismo mágico. Así, analiza la categoría como una apuesta que interconecta los esfuerzos asiáticolatinoamericanos por cuestionar la hegemonía discursiva que promueve una realidad singular/universal posibilitada por la racionalidad del realismo literario.

La mayor parte de los trabajos recopilados en este libro forman parte de una apuesta teórica, metodológica e investigativa que desdibuja las aproximaciones más tradicionales de las relaciones Asia-Latinoamérica. El actual panorama global insta a trazar en el contexto de producción de saber transpacífico, nuevas rutas de contacto para desarrollar estrategias políticas de efectos concretos, que resistan a los centros epistemológicos y defendiendo un Sur Global que a sí mismo se piense, se investigue y se nombre. 

